\title{
Contributing Factors to Long Working Hours: Case Study of Waiters in Dire Dawa Administration
}

\author{
Gizachew Girma, Tadesse Moges \\ School of Law, Dire Dawa University, Dire Dawa, Ethiopia \\ Email: gizachew2587@yahoo.com, tadessemoges@gmail.com
}

Received 7 June 2015; accepted 2 August 2015; published 5 August 2015

Copyright (C) 2015 by authors and Scientific Research Publishing Inc.

This work is licensed under the Creative Commons Attribution International License (CC BY). http://creativecommons.org/licenses/by/4.0/

(c) (i) Open Access

\section{Abstract}

The need to create and maintain industrial peace, in one hand, protect the fragile interest of workers on the other side to boost economic development have been critical issues which have attained significant consideration from states. To that end, they introduced at international and national levels different set of legislations regulating employment relations. Among other things, working time limit has meticulously been introduced to safeguard the rights of workers, who are generally with the lesser bargaining power, and make the labor more productive. Ethiopia has accepted this notion of delimitating working hours, and adopted legislations. However, it has become a public secret that such rules have not been maintained in practice and that the enforcement mechanism appeared meager. Though researches have been made in different part of the world; in Ethiopia, particularly in Dire Dawa, the factors contributing for long working hours have not been addressed. There are, however, indicators that particularly waiters are working for longer hours than what the law stipulates. In a town dubbed as industrial corner, this factor should not be left unconsidered if the aspired objective of the labour regulation is really to be met. This research, hence, took the first step in studying the existence of this violation, and investigating the contributing factors. The data were collected through structured questionnaires and interviews, and samples were taken using stratified systematic sampling method. Data were analyzed through quantitative (descriptive analysis and logistic regression model) and qualitative techniques. Then, job insecurity, lack of legal awareness, culture of the work, salary, tips, dependents, and level of education have been found out to be contributing factors, and their level of significance has also been established. It has also revealed that the absence of strong enforcement mechanisms contributed for the apparent non-adherence to the rules so delimiting working hours.

\section{Keywords}

Long Working Hours, 48 Hour Rule, Factors Job Insecurity, Lack of Legal Awareness, Culture of the 


\section{Work, Salary, Tips, Dependents, Level of Education}

\section{Introduction}

\subsection{Background}

Historically, labor has been considered as a commodity eligible of economic exchange. Accordingly, the relation of the worker and employer was left to private regulation through contract; where by the role of state is limited to enforcing the contract of the parties. Under the rubric of freedom of contract, a worker is used to be a commodity to be picked up and discharged at the employer's will and most of all susceptible to exploitation for longer working hours.

It is in view of reducing such injustice, not so much less to be termed as slavery; that the present day has called for states intervention in regulating labor relations. The reduction of working hours was one of the original objectives of labor laws. The primary technique towards achieving this goal, mandating of limits on the hours that can be worked in each day or week, was first reflected in laws enacted in European countries in the mid-nineteenth century to reduce the working hours of children (ILO, 1967).

These early, more limited, measures were followed by laws that addressed the working hours of adults, which spread across Europe, resulting in a ten hours daily limit being relatively widespread in this region by the start of World War I. While this was the high point of progress in Europe, however, two pioneer countries, New Zealand and the United States, had adopted a 48-hour a week at the beginning of the century. Soon after the end of the war, this standard had spread to most European and a number of Latin American countries, including Mexico and Uruguay. When union campaigns for global standards on working hours culminated in their inclusion in the Preamble to the ILO's Constitution and its first standard, the Hours of Work (Industry) Convention, 1919 (No. 1), it was the eight-hours a day and 48-hour a week that were included (Murray, 2001).

The significance of this initial standard of the 48-hour a week is that it is the legal standard closest to the point beyond which regular work becomes unhealthy, which is identified in the health literature as 50 hours (Spurgeon, 2003). Indeed, the preservation of workers' health was a primary strand in the adoption of this standard from its inception, and remains a prominent rationale of policies aimed at keeping working time within this limit. Health and safety was not, however, the sole objective underlying the 48-hour a week. Other goals were reflected, in the debates around the adoption of Convention No. 1, in which, although health and safety concerns were voiced, the dominant rationale was to ensure adequate non-work, or "leisure", time for workers (Lee et al., 2007).

The 48-hour limit did not, however, remain the only standard to be adopted at the national or international levels. By the 1920s, a number of industries in Europe and the United States had introduced 40-hour a week principle. And during the depression of the following decade, when hours reductions first came to be identified as having the potential to promote employment, it was embodied in a new international instrument, the Forty Hours a Week Convention, 1935 (No. 47), which refers to the hardship caused by widespread unemployment and requires measures to reduce working hours towards this standard.

Finally, in reviewing the evolution of working hours limit, it is also useful to recall that the concern for the limitation of working hours is not confined to labor law, but that it has also been identified as a human right. The right to limits on working hours is included in the human rights instruments that emerged in the wake of World War II, in which it is expressed in less concrete terms than in the ILO standards. The Universal Declaration of Human Rights (UDHR) recognizes a right to rest and leisure that encompasses a "reasonable limitation" of working hours; and the International Covenant on Economic, Social and Cultural Rights (ICESCR) includes working hours limits as elements of the right to a just and favorable working conditions.

As pointed above, by the mid-twentieth century two primary standards were available for limiting weekly working hours, the 48-hour limit of the earliest international instruments and the more recent objective of the 40-hour a week. The international standards and national legislation in the vast majority of countries share a similar structure, in that they specify a limit on the number of hours that can be worked before over-time payments are to be made, plus additional limits on overtime hours.

When we come to see the Ethiopian perspective, the laws dealing with the labor regime also follow almost the same trend. The FDRE Constitution, which is the supreme law of the land, recognizes workers' right to reasonable 
limitation of working hours, to rest and to leisure, to cite some. In tune with these stipulations, the Labor Proclamation No. 377/2003 prescribes the maximum number of working hours to be eight hours per day and/or 48 hours per week. This maximum working time regulation puts Ethiopia at the apex of the countries that have extended legal normal working hours while most countries adopt 40 hours as legal normal weekly working hours (Lee et al., 2007). It also recognizes workers right to paid and uninterrupted 24 hours weekly rest day.

Besides, the proclamation also puts limitation on overtime work in which it shall not exceed two hours in a day or 20 hours in a month or 100 hours in a year. Above all, the proclamation discourages the employer not to request workers for overtime works by obliging him/her to pay more wages that would otherwise be less had the worker worked in the normal working hours.

In practice, however, it has remained a public secret that respecting such minimum standards has not been observed in our country, in general, and Dire Dawa, in particular. To the best knowledge of the researchers, no well founded research has been conducted to know the underpinning causes, the adverse consequences thereof and no single effort has been made to tackle such problems. Interestingly enough, Dire Dawa University identified labor law issues as one of its research priority areas.

\subsection{Statement of the Problem}

The right of works to benefit from the minimum standards, inter alia, on the length of working hours, currently attaining universal acceptance has well been articulated under different international treaties, human rights covenants and domestic constitutions and legislations. Ethiopia is a party to more than 20 conventions and they are by virtue of Art. 9 (4) of the FDRE Constitution made part and parcel of the law of the land. The Ethiopian labour law also sets maximum working hours - eight hours per a day or 48 hours per a week with sufficient rest period for the workers. Hence, such rights of the workers should be respected by a state, principally, and other stakeholders as a matter of obligation.

Such restriction of working hours is made for different justifications, including but not limited to, maintain the effectiveness, motivation and productivity of workers, health, safety and other social and economic reasons. Accordingly, demanding the employee to work more than such maximum legal limit is illegal, irrespective of the fact that the worker so consented.

Despite the existence of these strict stipulations and legal obligations, in the preliminary investigations and observations made by the researchers on waiters working in different cafes, restaurants and hotels in Dire Dawa, it has been uncovered that most of such workers are working beyond the legal limits. The effectiveness of the monitoring mechanism is questionable that needs to be tested.

As the saying goes, "to cure an illness, it must be distinguished first", the contributing factors for such long hour working has to be discovered to put the appropriate solution in place. To the best of the researchers' knowledge, this problem has not yet been studied in Dire Dawa. Hence, this research identified the reasons for long working hours from different perspectives.

\subsection{Objectives of the Study}

\subsubsection{General Objective}

The general objective of this research is to probe the factors underpinning for non-observance of the rules dictating the maximum length of hours an employee is expected to work.

\subsubsection{Specific Objectives}

In line with the general objective, this research aims at addressing the issues:

$>$ Factors affecting longer working hours;

$>$ Addressing the issue of why working for long working hours from the workers' perspectives;

$>$ To address employers' understanding and perspective on working time regulations;

$>$ Examining the effectiveness of monitoring mechanism to ensure the observance of such laws is not put in place;

$>$ Pin-pointing the potential way outs that would help in rectifying the observed loopholes.

\section{Literature Review}

The review of the research literature shows that what constitutes "long hours working" is very much subject to debate and people's own assessments seem to be based upon their own direct experience, such that long hours 
working is perceived as a significant departure from their normal working week. There appears to be three ways of examining long hours.

The first is determined by workers perception on his/her hours of work or whether or not the workers would like to maintain or reduce, or even increase, their working hours. In this case long working hours is a situation where employees wanted to work fewer hours than they did (Lee et al., 2007). The second way takes one of the primary perceived objectives of delimiting minimum working hours-negative consequences on workers especially the effects on health and safety. Here long working hours is where an employee works exceeding the maximum hours beyond which negative consequences on workers are known to be visible (Lee et al., 2007). The other way of delimiting long hours is by taking the legal limits as a bench mark. This is with the assumption that legal normal hours determine a socially acceptable level of working hours. Thus here long working hours is where employees works exceeding the legal normal hours (Lee et al., 2007).

Taking into account ILO Hours of Work (Industry) Convention, 1919 (No. 1) to which Ethiopia is a party and in line with Ethiopia's present labour proclamation which stipulates 8 hours per day and 48 hours per week as normal working hours, for the purpose of this research, long hours working is defined as "a work done for more than 8 hours per day and 48 hours per week".

There are number of studies that are made to demonstrate the negative effect of working long hours on Employment and productivity (Kodz et al., 2003), work performance and related risks (Harrison \& Horne, 2000; Kirkcaldy, Trimpop, \& Cooper, 1997), health and safety (Harrington, 2001; Van der Hulst, 2003), motivation to and absence from work (Baker, Heiler, \& Ferguson, 2003), family and other social relations and responsibilities of the worker (Glezer \& Walcott, 1999).

Despite the bulk of research findings on the negative impact of long working hours and enactment of working time regulation delimiting the maximum working hours and setting up enforcement institutions, long hours working is common problem in almost all countries of the world (Lee et al., 2007). Mainly due to reasons attributable to the level of income inequality and the existence of legal and collective contractual regulations delimiting normal working hours, incidence of long hours working varied across countries (Kodz et al., 2003). In Ethiopia the incidence of long hours working is very high compared to many other countries, in which more than 41 percent of all employees are reported to work more than 48 hours per a week (Kodz et al., 2003).

Why are employees working long hours attract the attention of many researchers in foreign countries. Different scholars give different justification and different studies reveal different findings in answering this basic question. Literatures on who works and why they work for long hours are discussed underneath.

The incidence of long working hour varies with the job (work place) and workers characteristics. Average weekly hours in general and incidence of long working hour in particular are comparatively high in the mining, Accommodation, Cafes and Restaurants, Transport and Storage and construction sector (Dawson, McCulloch, \& Baker, 2001). Even among the various service subsectors, average weekly hours of work are particularly long in wholesale and retail trade, hotels and restaurants, and transport, storage and communications, while it is short in education (Lee et al., 2007).

While there is some variation, studies make it clear that long working hours are prevalent in most occupations (Dawson, McCulloch, \& Baker, 2001). However, a study in USA founds that managers and professionals who typically have jobs with greater responsibilities are more overworked than others (Ellen et al., 2004). This finding is also supported by another study in Australia (Dawson, 2001).

In addition the qualification of the worker-whether he/she possesses a degree or above, diploma and other qualifications-have a direct relation with weekly working hours. A study indicates that the higher the level of the qualification possessed, the more likely the individual is to work long hours (Kodz et al., 2003). Another study also concludes that educated workers were more likely to work long hours than less-educated workers (Kuhn \& Lozano, 2005).

Studies show that there is clearly a gender difference in terms of long working hours and as such gender is clearly a crucial factor differentiating working hours among workers. Even though women are increasingly engaged in the paid workforce, a higher proportion of males than females work long hours (Kodz et al., 2003). A study justifies the disparity to the temporal availability of women for paid work is significantly constrained by the time that they need to devote to their household/domestic responsibilities (Lee et al, 2007). Analysis of other factors or multi-variate analysis also shows that the propensity to work long hours is associated with gender (Kodz et al., 2003). Contrary to many researches, one study concludes that women are somewhat more overworked than men attributable to a reason that women job requires multi-tasking more than men do (Ellen et al., 
2004). Studies shows that there is no real significant difference between marital status groups in the extent to which they work long hours, with only those who are widowed being slightly less likely to work long hours than the other groups (Kodz et al., 2003).

Studies also revealed that the likelihood of working long hours varies with age, with those who are most likely to work long hours in their job aged between 30 and 49 years old, with a peak in the 30 to 39 age group (Kodz et al., 2003). When working long hours by age group and gender is considered, the peak for both males and females is within the 30 to 39 age group, closely followed by those in the 40 to 49 age group (Kodz et al., 2003). However, a higher proportion of women work longer hours when they are younger, while men, are more likely to work long hours in their o 40s and 50s (Kodz et al., 2003). Other research, however, alleges that working long hours is a function of the kinds of jobs employees have, not their age or generation (Ellen et al., 2004).

Unsurprisingly, a study indicates that those with longstanding health problems or disabilities are slightly more likely not to be working long hours than those without (Kodz et al., 2003). Looking at whether having any dependants would make any difference to those working long hours, the studies suggests that while women with children are less likely to work long hours than are their female counterparts without dependent children, while the opposite is true for men (Kodz et al., 2003).

Modality of payment, amount of wage and the existence of overtime payment were raised as factors for long working hours. Concerning the modality of payment it is said that salaried men are much more likely to work long hours than hourly-paid men (Kuhn \& Lozano, 2005). Studies vary on the cross sectional relation between rate of wage and long working hours. In a comparative study between two periods (1979 and 2006) on the cross sectional relation between rate of wage and long working hours, reversed results were found (Kuhn \& Lozano, 2005). That is in 1979, the worst-paid 20 percent of workers were more likely to put in long work hours than the top 20 percent; by 2006 the top 20 percent were twice as likely to work long hours than the bottom 20 (Kuhn \& Lozano, 2005). But bulk of studies support that low paid workers are more likely to work for long hours. A study in the Philippines, for example, has shown that low hourly pay and long working hours are significantly correlated, even concluding that "long hours of work are a reasonably good indicator of low-hourly pay for time-rated wage and salary workers" (Mehran, 2005). The reasons given for this phenomenon is that low hourly rates of pay rely on overtime as a means of supplementing their weekly wage (Lee et al., 2007). That is, when workers wage is low, an aspiration to obtain or maintain higher incomes derived from overtime payment can induce workers to work for longer hours. Thus it is held that there is clear relation between reasons for long hour work and whether overtime is paid or not paid. As studies indicate where overtime is rewarded, the main reason for working long hours is to increase pay (Peetz, 2003). Since working for long hours might be employer driven (Peetz, 2003), the strength and validity of this factor is mainly dependent upon workers ability to choose the length of hours he/she is expected to work. This choice will reflect a balance between their need for income (where longer hours generates more income) and the constraints faced in working longer hours (such as the need to care for children) (Hogarth et al., 2001).

Pay is also cited as an impetus to work long hours even where overtime is not paid. That is, workers also work unpaid overtime in anticipation of higher earnings in the future as hard working will enhance chances of promotion (Kodz et al., 2003). In addition, where overtime is not rewarded, which is most common amongst managerial and professional workers the requirements of the job and workload or the volume of work was seen to be a key driver of long working hours (Kodz et al., 2003). Factors perceived to be associated with increasing volumes of work relate to new organizational initiatives; including flattening organizational structures due to de-layering, increases in project based working, a greater emphasis on customer focus, meetings culture, understaffing, sickness cover and increasing need for some employees to travel for their work (Kodz et al., 2003). Workload and associated factors are also the main reasons for long working hours raised by employers (Hogarth et al., 2001).

As pointed above long hour work might be employer driven, since workers control over the length of hours is little. This is due to the mechanics of work place power relations between the worker and employer. Thus workers have little choice regarding working long hours and are expected to work additional hours. In this case perceived job insecurity can be a driver for working long hours. People fearing redundancy may work long hours in an effort to prove their indispensability, it is more likely in workplaces where redundancies have taken place, or are expected (Kodz et al., 2003).

Employees' attitude to work is also mentioned as one factor for long hour working. It appears that those who work over 48 hours per week are those who feel that they never have enough time in their working day to get 
their job done and also are those who worry a lot about their work outside working hours (Peetz, 2003). Related to attitude to work long hours working claimed to be associated with particular forms of workplace culture of working long hours perceived by employees-i.e. a situation where long hours have become the norm (Laurence, et al., 2004).

The existence and effectiveness of working time regulatory and institutional framework also affects long working hours negatively. Studies in UK found that unionization reduces the prevalence and extent of overtime hours (Kodz et al., 2003). In contrast, a study in Australia argued that the presence of unions was associated with prolonged hours of work and concludes that union members are more likely than non-members to work long hours because they are more likely to have long tenure with the employer, but union members are more likely than non-members to be compensated for working long, or increasing, hours (Peetz, 2003).

\section{Research Methods and Methodology}

\subsection{Overview of the Study Area}

Dire Dawa - one of the chartered cities of Ethiopia-was founded in 1902 after the Addis Ababa-Djibouti railway was under construction. The railway makes the city one of the principal trade center of the country. According to the 2007 national Census, Dire Dawa has a population of 341,834, of whom 171,461 are men and 170,461 women; 233,224 or $68.23 \%$ of the population are urban inhabitants. For all of Dire Dawa 76,815 households were counted living in 72,937 housing units, which results in an average of 4.5 persons to a household, with urban households having on average 4.2 and rural households 4.9 people. Ethnic groups in the region include the Oromo (45.9\%), Somali (24.3\%), Amhara (20.17\%), Gurage (4.55\%), Tigray (1.23\%), and Harari (1.09\%). Languages spoke include Oromiffa (47.95\%), Amharic (19.7\%), Somali (26.46\%), Gurage (2.78\%), and Harari (1.04\%). The religion with the most believers in Dire Dawa is Muslim with 70.8\%, 25.71\% are Ethiopian Orthodox, 2.81\% Protestant, and $0.43 \%$ Catholic.

\subsection{Data Collection and Study Variables}

The study showed the factors for long working hours by waiters. The data were collected using structured questionnaires which were designed so as to incorporate the variables in the context of the study. Two different sets of questionnaires for waiters and managers/supervisors were set. The questionnaire for waiters (Annex 1) has 27 closed and open ended questions. It has also likert scale items. And the questionnaire for managers/supervisors (Annex 2) included 36 questions (closed and open ended). The questionnaires were prepared in English and then translated in to Amharic maintaining its consistency and interview method was done by the researchers to obtain further qualitative data. Data were collected by Dire Dawa University Law School graduating class students from waiters and managers/supervisors. Interviews of 10 key informants (two judges, four officials and four worker) were also made to get more information on the legal enforcement mechanisms. A total of 146 individuals were made participants of the study through filling the structured questioners. Among them 121 were waiters working and 25 were representatives of hotels.

When we look into the variables of the study, the dependent variable is the engagement of waiters on overload works in both categories of hotels, i.e. whether the waiters are working overload or not. This was calculated from self reported daily and weekly working hours and further classifying based on the time limit set by the law. While the independent variables of the study included those relating to: socio-demographic (age, sex, marital status, educational status, dependents); Legal knowledge and attitude about (working hours and rest and leave days); customer and working environment related variables; employment related variables (duration, job security, promotion, under-staffing, and salary); personal (desire) and those related to benefits the waiters; and socioeconomic variables (family, health, and other social affairs) have been tested.

\subsection{Sampling Design and Sample Size Determination}

\subsubsection{Sample Design}

The target population of waiters was first stratified in to those working in Hotels with Star and those working in Hotels without star (including cafes and restaurants) assuming that heterogeneity exists across the hotel types, and waiters in similar hotel type are homogeneous. Next hotels from both categories, i.e. from the star and non-star, were selected using systematic random sampling taking the list of the names of the hotels as a frame. 
Final sampling units, waiters, were sampling again using systematic sampling from their respective strata by developing an on-field sample frame as recommended by UN (2008). Hence, the sample design used was Multistage stratified systematic sampling.

\subsubsection{Sample Size Determination}

Due to the absence of information on the proportion of waiters working overload, the sample size was determined by setting both p and $q$ to 0.5 , with 0.08 marginal error and $95 \%$ CI $(\alpha=0.05)$. Based on this assumption, the actual sample size for the study was determined using the following formula (Ministry of Industry, 2010) (Survey Methods and Practices, Statistics Canada, 2010):

$$
n=\frac{Z_{\alpha / 2}^{2} p q}{d^{2}+\frac{Z_{\alpha / 2}^{2} p q}{N}}=\frac{1.96^{2}(0.5)(0.5)}{0.08485+\frac{1.96^{2}(0.5)(0.5)}{1355}}=121
$$

where:

$n=$ the required sample size

$z=$ standard score corresponding to $95 \%$ CI

$p=$ Proportion of waiters working overload

$d=$ the margin of error

For the Primary stage sampling units, from a total of seven with star hotels two were selected using One-inThree systematic sampling and from without star hotels 48 were selected using One-in-Five systematic sampling.

For the final sampling units, fifteen waiters from with star hotels were picked using One-in-Three systematic sampling units and One Hundred Five waiters from without star hotels were selected using One-in-Two systematic sampling.

Furthermore purposive sampling of Hotel managers/supervisors was done to further triangulate the data and assess the legal knowledge of the employers using descriptive analysis.

\subsection{Method of Data Analysis}

\subsubsection{Data Processing and Analysis}

Initially data template format was prepared using EPINFO version 7 and then imported to SPSS version 21 for analysis. Each questionnaire was given a unique Identification number to enter the computer and trace for checking. Univariate analysis such as proportions, percentages, frequency distributions and appropriate graphic presentations in addition to measures of central tendency was described for variables related to socio-demographic characteristics, Legal knowledge and related variables. Binary logistic regression was used to identify factors that affect overload work of waiters and the significance of the variables was compared with $\mathrm{P}$ value $=$ 0.05 .

\subsubsection{Logistic Regression Model}

Taking one target dependent variables (working overload or not) and Seven predictors (Job security, Salary, Educational background, Legal knowledge, Tips, Dependent, attitude) a Binary Logistic regression model was fit.

Binary Logistic regression model analyses for binary out comes attempt to model the odds of an event's occurrence and to estimate the effects of independent/predictor variables on those odds. The odds of an even is a quotient that conveniently compares the probability that an event occurs (referred to as "Success") to the probability that it does not occur (referred to as "Failure", or the complement of success). When the probability of a success is greater than the probability of failure, the odds are greater than 1.0; if the two outcomes are equally likely, the odds are 1.0; and if the probability of success is less than the probability of failure, the odds are less than 1.0.

In our study (Working overload) the outcome can be described as binary: Yes or No where "yes" could represent success and "No" could represent failure in the regression model. If the variable is represented by $\mathrm{Y}$ the two events could be denoted as $Y=1$ and $Y=0$ for "yes" and "No" respectively. The odds of "working overload" are computed from the sample data by dividing the probability of the answer "yes" (scored as $Y=1$ ) 
by the probability of answer "No" (scored as $Y=0$ ).

$$
\text { Odds }=\frac{P(Y=1)}{P(Y=0)}=\frac{P(Y=1)}{1-P(Y=1)}
$$

Parameter Estimation and Hypothesis Testing:

Parameter estimation was done by maximum likelihood estimation and the significance of the parameters hypothesis was checked by the Wald test.

Goodness-of-fit of Model:

The goodness-of fit of the model was assessed by Hosmer and Lem show test together with the Cox and Snell's R-square value.

Regarding presence of any assumptions of the model one advantage of the logistic regression is, it gives some relaxation with respect to the usual Ordinal Least Square assumptions. There are, however, other considerations one should pay attention for efficient use of the model such as proper coding of the variables, inclusion of all relevant predictors, and independence of the error terms.

\section{Results}

This chapter deals with the analysis and interpretation of the data gathered through questionnaires from workers and employers and interviews with key informants. Data were scrutinized and carefully entered in order to endure accuracy and verify for the missing, inconsistent and incomplete information. First the data were feed into Epi Info and exported to SPSS V21 for detailed analysis. Descriptive analysis methods i.e. mean, percentage, cross tabulation and chi-square test of association. It is known that chi-square test would enable one to establish/see the relationship of dependant variable and other variables, and this test has been widely used method in social science studies. In addition, binary logistic regression model has been used to identify which factors and to the level of significance each contributing factors for long working hours has had. Furthermore, qualitative analyses have been made based on the data acquired through interviews and open ended questions. This has been found significant in substantiating results acquired in the qualitative analysis.

Moreover, the assumption taken i.e. the waiters in Dire Dawa are doing for longer hours, is valid. For the waiters are doing on average for about 11 hours (responses of workers) and 8.8 hours (responses of employers). The study considers overtime work as a work done for more than eight hours per day or forty-eight hours per week. In the subsequent part detailed presentation of the results of the study is presented.

\subsection{Description of the Study Variables}

\section{1) Demographic and socio economic variables}

A total of 146 individuals were made participants of the study through filling the structured questioners. Among them 121 were waiters working and 25 were representatives of hotels. From the participants of the study representing waiters, as indicated in Table 1, 63 (52.1\%) were females and the remaining were males, while those representing employers 20 (80\%) were males and the rest were females. Age wise, 118 (97.5\%) of the waiters have attained the age of majority while 3 (2.5\%) were under age.

The education levels of the respondents were also classified in to three categories of waiters: those having diplomas or above, those not having diploma but above grade ten, and bellow grade ten. As indicated in Table 1, it was found out that $22.3 \%$ were diploma holders, while $27.3 \%$ of the respondents completed grade 10 and the significant number $50.4 \%$ were below grade ten. Whereas, among the managers $36 \%$ of them have Diploma and the rest only high school graduates.

Moreover, majority of the waiters were found out to be single which constitutes $83.1 \%$ of the respondents. And $9.3 \%$ of the respondents are married, $2.5 \%$ divorced and the rest, i.e. were $5.1 \%$ who lost their spouses. From the total respondents $39.3 \%$ of them have one or more dependents while the remaining stated that they have none as dependents. Of those who replied in positive for having dependents 48 (39.6\%), majority of them support their parents which counts for $57.9 \%$ the remaining dependents were children $(29.8 \%)$ and others (12.3\%).

\section{2) Legal knowledge and attitude about working hours}

The study has investigated variables relating to the labor law and attitude of workers on overtime works. Out of the total waiters $91.7 \%$ of them responded that they have employment contract with their employer of which 
Table 1. Demographic variables v overtime works.

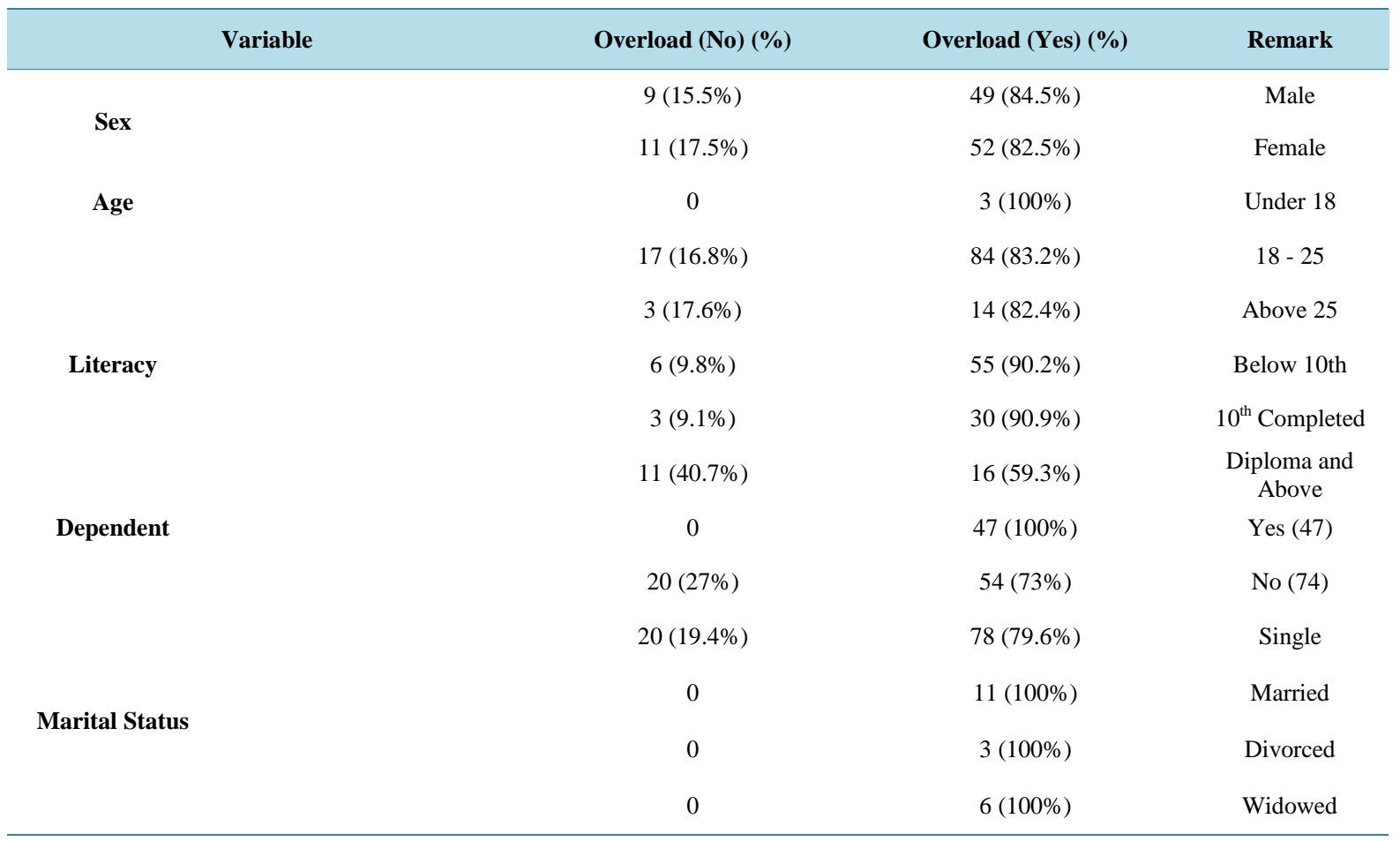

$76.6 \%$ concluded contracts orally while only $23.4 \%$ of them concluded a written contract. The remaining $8.3 \%$ of the waiters stated that they not negotiated terms and concluded contracts with their employers. Form the employers side, it was asserted on almost a parallel manner that mostly they conclude contract with workers (92\%). The main difference lies on the fact that the form of contracts concluded between the parties is whether an oral or written agreement. In this regard, $78.3 \%$ of the employers indicated that they have written contracts with their workers, while $17.4 \%$ asserted to have only oral contracts (see Table 2).

The study has a variable relating to the nature of the contract/employment. There, 47 (54.7\%) of the waiters replied that their contract is a temporary one and only 39 (45.3\%) know that it is a contract for indefinite time. What is more brain-teasing is that $20.4 \%$ of the waiters indicated no time is fixed in their agreements and $24.8 \%$ of them responded that they do not know whether there is a time provision in their agreement with their respective employers. Of the total waiters who were respondents, $57.9 \%$ of them do not know the fact that there exists a law delimiting working hours for employees and the rest 51 (42.1\%) replied they know the legal limits. However, of those who claimed to know the legal limits, 51 respondents, (3 individuals) 5.9\% do not exactly know the limit, which is eight hours per day or forty eight hours average per week (see Table 2).

In addition, among the total waiters only 26 (21.5\%) of them feel that they are not working for long hours, while the rest 95 (78.5\%) believe that they have been working for long hours each day. However, still significant number of the respondents 77 (63.6\%) desire to work for longer hours for different reasons. The study also investigated the factors why those who believe they work long hours, do so; and whether they could challenged that had they known or if they are let to know their rights, on one hand and the reasons for those who did not work. Then, $21.5 \%$ of those who believe to work overtime indicated that they were compelled by their respective employers, $15.1 \%$ of them responded that they lack legal awareness to challenge it, and $47.3 \%$ of them believed that it is the nature of their job. Among those who claimed not to work overtime 26 respondents (21.5\%), 6 of them (23.1\%) claimed that it is because of their entitlements not to do overtime works, 13 of them (50\%) for there are sufficient workers, 4 respondents (15.4\%) because they did not want to do it, and 11 individuals (42.3\%) indicated that they were prohibited by their employers (see Table 2).

In addition, the study also assessed whether there were waiters who have challenged working overtime and, and if they could do so after being informed of their rights. It is found out that from those who are made to know that they are not obliged to work overtime (90 respondents), only 10 individuals (11.4\%) responded in positive. 
Table 2. Legal knowledge and attitude related variables v overload.

\begin{tabular}{|c|c|c|c|}
\hline \multicolumn{2}{|c|}{ Variable } & Overload (No) (\%) & Overload (Yes) (\%) \\
\hline \multirow[t]{2}{*}{ Empt. Contract } & $\begin{array}{c}\text { Yes-111 }(91.7 \%) \\
\text { Oral-(76.6\%) } \\
\text { Written-(23.4\%) }\end{array}$ & $18(16.2 \%)$ & $93(83.8 \%)$ \\
\hline & No-10 (8.3\%) & $8(80 \%)$ & $2(20 \%)$ \\
\hline \multirow{2}{*}{ For definite pd } & Yes $47(54.7 \%)$ & $6(12.8 \%)$ & $41(87.2 \%)$ \\
\hline & No $39(45.3 \%)$ & $11(28.2 \%)$ & $28(71.8 \%)$ \\
\hline \multirow{3}{*}{ Agreement as to Hours } & Yes (54.9\%) & $14(22.6 \%)$ & $48(77.4 \%)$ \\
\hline & No (20.4\%) & $3(13 \%)$ & $20(87 \%)$ \\
\hline & Don’t Know (24.8\%) & $3(10.7 \%)$ & 25 (89.3\%) \\
\hline \multirow{2}{*}{$\begin{array}{l}\text { Awareness of the } \\
\text { law delimiting hours }\end{array}$} & Yes 51(42.1) & 10 (19.6\%) & $41(80.4 \%)$ \\
\hline & No 70 (57.9) & $10(14.3 \%)$ & $60(85.7 \%)$ \\
\hline \multirow{2}{*}{ Weekly Rest } & Yes 61 (51.7\%) & $7(11.5 \%)$ & $54(88.5 \%)$ \\
\hline & No 57 (48.3\%) & $13(22.8 \%)$ & $44(77.2 \%)$ \\
\hline
\end{tabular}

And from the total respondents 90 , only (16) $17.8 \%$ of them have said that they would challenge not to work after such awareness and (72) 80\% replied in the negative for different reasons, and the rest 2 respondents (2.2\%) were indifferent to it (see Table 2).

The participants of the study were also asked if they have been granted a weekly rest day and different forms of leaves they are entitled to by law with or without pay. Out of 121 respondents, 118 of them replied either in the positive or negative while 3 represented missing element. Of those who replied, 61 (51.7\%) of them stated that they have had a weekly rest day while the rest 57 (48.3\%) replied in the negative. Out of these 57 respondents 39 (68.4\%) have claimed for their right but denied; while 14 (24.6\%) and 4 (7\%) of them responded that they do not want it and they lack awareness about it respectively (see Table 2)

Pertaining to other sorts of leaves, out of 115 respondents (6 missing), 52 (45.2\%) of them were not given any sort of leave paid or unpaid; 23 (20\%) were given unpaid leaves; 35 (30.4\%) stated they have had sometimes paid and sometimes unpaid leaves; and only 5 (4.3\%) claimed they were given paid leaves always (see Table 2).

The study also tried to probe into the possible factors for not challenging their employers; and out of 107 respondents 39 (36.4\%) of them cited that it is beneficial for them; out of 106 respondents 12 (11.3\%) indicated that they would get overtime allowance; out of 107 respondents 25 (23.4\%) replied that there are no accessible enforcement mechanisms or they do not know where to ask for such remedies; and out of 109 respondents 30 (27.5\%) of them believed that their employers would not give any solution or consider their requests (see Table 2).

When we took the managers view in perspective, they have said that they recruit workers through brokers (44\%) or through vacancy announcement (56\%). In addition, significant number of managers/supervisors 12 (48\%) are found out to be owners or having family relation with the owner (see Table 2).

They also stated that they have had formal agreements with the waiters (92\%) while few of them admitted to have no undertakings with the workers (2\%). Of those who replied to have contracts, $78.3 \%$ have written agreements while the rest made oral undertakings. Regarding their legal awareness of the time limits for workers, most of them 23 (95.8\%) have replied in the positive while only 2 (4.2) said they do not know the rules. Furthermore, the study has investigated whether weekly rest is given by the employers. Here, 18 (72\%) replied in the positive while 6 (24\%) said no such leave (one missing element). The study also looked into the perception of managers relating to long working hours. The weekly average hours for workers were indicted to be beyond 48 hrs by 12 (48\%) of the respondents and 12 (48\%) of them indicted that the average working hours of 56 hrs and 1 (4\%) respondent indicated $64 \mathrm{hrs}$. It is found out that $19(79.2 \%)$ of them do not believe that their workers are working for longer hours, while the rest believe that waiters are working longer hours (see Table 2). 
Apart from this, the significant number of managers accepted that they did not meet the legal requirement of providing necessary trainings for the workers including building their legal awareness 11 (44\%) (see Table 2).

\section{3) Customer and working environment related variables}

The respondents were also asked about the influences of customer and other working environment related issues which were believed to have affected the working hours. In this regard, among the waiters only $30.2 \%$ of them responded that they are satisfied by their working environment, and about $25 \%$ of them were indifferent to their working environment. Meanwhile, those who responded very dissatisfied and dissatisfied stand on the same rank i.e. $19 \%$ while only 6.9 have responded that they are very much satisfied with the working conditions. However, when we specifically look at their satisfaction relating to their work schedule, a significant percentage $19.8 \%$ of them were very dissatisfied and $10.3 \%$ were dissatisfied. $37.9 \%$ of them were satisfied with their schedules, only $8.6 \%$ of them very much satisfied with their working time schedule (see Table 3 ).

When the relationship waiters have had with the customers and their supervisors is measured, they tend to have positive relation with customers than their respective supervisors. $19.8 \%$ and $12.9 \%$ of the waiters were found out to be dissatisfied and very dissatisfied respectively. Significant percentage i.e. $24.1 \%$ remained neutral while those who indicated that they have been satisfied and very satisfied both stood on $21.6 \%$. On the other hand, most of the respondents, $52.7 \%$ of them, were very satisfied with their interaction with customers they serve, and $28.2 \%$ of them were found satisfied. The rest $11.8 \%$ and $3.6 \%$ of them were those who replied to have been very dissatisfied and dissatisfied respectively (see Table 3).

Table 3. Customer and working environment related variables.

\begin{tabular}{|c|c|c|c|c|}
\hline Variables & Scales & Overload (No) (\%) & Overload (Yes) (\%) & Remark \\
\hline \multirow{5}{*}{ General working Env't } & Very Dissatisfied & 0 & $22(100 \%)$ & \\
\hline & Dissatisfied & $3(14 \%)$ & $19(86 \%)$ & \\
\hline & Neutral & $10(34.5 \%)$ & 19 (65.5\%) & \\
\hline & Satisfied & 7 (20\%) & $28(80 \%)$ & \\
\hline & Very satisfied & 0 & $8(100 \%)$ & \\
\hline \multirow{5}{*}{ Waiter-Manager relation } & Very Dissatisfied & $3(20 \%)$ & $12(80 \%)$ & \\
\hline & Dissatisfied & $3(13 \%)$ & 20 (87\%) & \\
\hline & Neutral & $6(21.5 \%)$ & $22(78.5 \%)$ & \\
\hline & Satisfied & $3(12 \%)$ & $22(88 \%)$ & \\
\hline & Very satisfied & $5(20 \%)$ & $20(80 \%)$ & \\
\hline \multirow{5}{*}{ Waiter-Waiter relation } & Very Dissatisfied & $5(31 \%)$ & $11(69 \%)$ & \\
\hline & Dissatisfied & 0 & $2(100 \%)$ & \\
\hline & Neutral & $3(25 \%)$ & $9(75 \%)$ & \\
\hline & Satisfied & $1(4 \%)$ & 24 (96\%) & \\
\hline & Very satisfied & $11(18 \%)$ & $50(82 \%)$ & \\
\hline \multirow{5}{*}{ Waiter-Customer relation } & Very Dissatisfied & $2(15 \%)$ & $11(85 \%)$ & \\
\hline & Dissatisfied & 0 & $4(100 \%)$ & \\
\hline & Neutral & 0 & $4(100 \%)$ & \\
\hline & Satisfied & $10(32 \%)$ & $21(68 \%)$ & \\
\hline & Very satisfied & $8(14 \%)$ & $50(86 \%)$ & \\
\hline
\end{tabular}


Moreover, most waiters (52.6\%) have responded that they are very much satisfied with their relation to one another, and $20.7 \%$ of them replied satisfied with such relation. Of course, significant percentage is also indicated as very dissatisfactory i.e. $13.8 \%$ (see Table 3 ).

From the perspective of employers, the study revealed that almost all 24 (92\%) of the respondents do believe that the working environment is not that convenient for the waiters while 2 (8\%) respondents state there is conducive working environment. However, most of them 22 (88\%) believe that they have had an excellent relation with their workers while the rest indicated a good working relation (see Table 3).

\section{4) Employment related variables}

The study also included employment related variables. To that end issues including duration, job security, promotion, under-staffing, and salary have been tested. The study found out that $45.3 \%$ of the waiters have a permanent work while 47 (54.7\%) of them were temporary workers and the rest 39 (45.3\%) claimed to be permanent workers. When asked about whether they have job security, $32.2 \%$ of the waiters responded that they strongly disagree stressing that their job is not secured one while $31.3 \%$ of them remained neutral/feel indifferent to respond to it/. $27 \%$ of the waiters feel like their work is a secured one while $6.1 \%$ of the total respondents strongly believe that they are secured. Job security issue has also been indicated as a factor for not requesting their rights which they know previously or after being informed of the law entitling them not to work overtime by 75 (67\%) of the respondents out of 112 respondents (see Table 4).

Among the respondent waiters $52.2 \%$ of them believed that they have no chance of promotion, while $8.8 \%$ of them disagree with the existence of a chance for promotion. $21.2 \%$ of the respondents remained neutral and the remaining $7.1 \%$ and $8 \%$ responded that they agree and strongly agree to the existence of promotion respectively. Related to this question, the study further examines whether expectation of promotion have got influence on requesting the right not to work overtime, and out of 109 respondents, 6 (5.5\%) indicated it as a reason (see Table 4).

The study also assessed whether the waiters believe that there are sufficient workers for the tasks in their respective institutions. To that end, half of the respondents (50\%) replied that their institutions are understaffed. On the same vein, the study assessed the salary level and satisfaction of waiters regarding their wages. Among the respondents $45.7 \%$ of them were very dissatisfied with the salary scale, and $25.9 \%$ of them were dissatisfied on their salary. The rest respondents replied as satisfied (17\%) and very satisfied (1.7\%). In addition, the waiters were asked whether they still want to do overtime work if their salary is increased. Of the total 111 respondents to this question, 67 of them (60.4\%) replied in the positive while only 44 waiters (39.6\%) replied in the negative (see Table 4).

The data from the managers indicate that the proportion of waiters to the works they have had is enough which constitutes 20 (80\%). Whereas, 2 (8\%) respondents believe that there are more than enough workers and the remaining 3 (12\%) believed that there is understaffing (see Table 4).

\section{5) Personal and Benefit related variables:}

This study also included variables which are purely personal and those related to benefits the waiters acquire in doing their works. The respondents were asked whether factors associated to their personal feelings and/or

\section{Table 4. Employment related variables v overload.}

\begin{tabular}{|c|c|c|c|c|}
\hline Variable & & Overload (No) (\%) & Overload (Yes) (\%) & Remark \\
\hline \multirow{4}{*}{ Job security } & Yes 38 (32.2\%) & $12(31.6 \%)$ & $26(68.4 \%)$ & \\
\hline & No $41(33.1 \%)$ & $3(7.3 \%)$ & $38(92.7 \%)$ & \\
\hline & Indifferent 36 (31.3\%) & $5(14 \%)$ & $31(86 \%)$ & \\
\hline & Yes 22 (18.18 \%) & $6(27.3 \%)$ & $16(72.7 \%)$ & \\
\hline \multirow[t]{2}{*}{ Satisfied with salary } & No $83(68.5 \%)$ & $12(14.5 \%)$ & $71(85.5 \%)$ & \\
\hline & Indifferent 16 (13.22\%) & $3(19 \%)$ & $13(81 \%)$ & \\
\hline \multirow{2}{*}{ Desire for overtime after salary increment } & Yes $67(60.4 \%)$ & $12(18 \%)$ & $55(82 \%)$ & \\
\hline & No 44 (39.6\%) & $5(11.4 \%)$ & $39(88.6 \%)$ & \\
\hline
\end{tabular}


benefit related issues made them get involved in overtime works. Of the total 121 respondents, 58 of them indicated that they have been getting tips and the average/mean/money they get is 21.24 Birr per day. Those working in hotels with star (15) got on average receive $29.3 \mathrm{Br}$, while those working in hotels without stars earn $19.00 \mathrm{Br}$. The respondents were also asked whether they receive other benefits such as service charges and other extraneous payments. To this question only 51 respondents get positive reply. Plus of the workers who desire to work long hours and indicated reasons (68 respondents) 50 (73.5\%) of them mentioned additional income as a triggering element. Furthermore, the waiters stated that mostly they were not paid for overtime works 62 (95.2\%) and only 3 (4.8\%) of them indicated that they were paid (or payment is there) for overtime works (see Table 5).

In relation to personal factors, of those who responded to work overtime work 93, 21 (22.6\%) of them responded to work overtime for personal reasons. In the same vein, waiters were also asked whether they desire to do for overtime works, and 77 of the total respondents answered in the positive though only 62 of them have indicated their reasons. From the reasons provided, 6 (9.7\%) of them indicated staying out of their home as a reason (not a sole reason necessarily) and 10 (16.1\%) of them portrait they enjoy their work, as factors. In another question related to this variable, when asked why they failed to challenge the employer against overtime work; out of 109 respondents only 3 (2.8\%) considered it as a contributing element to that end (see Table 2).

\section{4) Other Socio-economic Variables}

The study further considered the possible influences that education, health, family and social affairs would pose on the length of hours one could work. For instance, among those who have claimed to have no desire for overtime work 44 (36.4\%) of the total respondents 35 of them indicated their reasons. Of those 35, 6 (17.1\%) indicated health problem; 13 (37.1\%) of them included family responsibility; 9 (25.7\%) of them refer to education; and 16 (45.7\%) of them encircled social affairs as hindering them from working overtime.

\subsection{Logistic Regression Analysis}

Binary logistic regression was fit to assess whether the seven predictors Legal knowledge, tips, Salary, norm, job security, and dependent significantly predicted the overload working status of the waiters. As presented in the table below five of the predictors (Job security, literacy, tips, legal knowledge and dependency) turned out to be statistically significant taking a significant level of Alpha $=0.05$. Waiters that reported to have legal knowledge are about (0.317) less likely to work overload and those who reported to feel insecure about their job are 11.846 times more likely to work overload than those who do not feel so. Regarding the tip they receive, waiters getting a tip above 21.2 Birr are $1.425(0.264,7.679)$ times more likely to work overload than those getting a tip less than the average tips. Waiters those reported to have dependents are 6.166 times more likely to work overload than respondents living without any dependent. Literacy status analysis also resulted that waiters who are only Grade $10^{\text {th }}$ complete are 32.392 times more likely to workload than respondents with Diploma level educational background (see Table 6).

So also, the model summary in Table 6 revealed that the model fits the data well with NegelkerkeR2 value of $52.3 \%$ and confirming result from the Hosmer and Lem show test of model goodness.

\subsection{Qualitative Analysis}

We also assessed the attitudes of waiters and employers towards long working hours in open ended questions, and mostly workers indicated that they could not raise issues of rights and other benefit related claims either because they feel there would be no response or their employers would fire them. The attitude of employers towards the legal limits also appears to be somehow incompatible to the expectations of the law for most of them appear to be against the eight hours legal limits. The perception towards the working environment and salary issues

Table 5. Personal and benefit related variables.

\begin{tabular}{|c|c|c|c|c|}
\hline \multicolumn{2}{|c|}{ Variables } & Overload (No) & Overload (Yes) (\%) & Remark \\
\hline \multicolumn{2}{|c|}{ Personal reason } & 0 & $21(100 \%)$ & \\
\hline \multirow{2}{*}{ Benefit related } & Tips & $3(22.5 \%)$ & 45 (77.5\%) & \\
\hline & Other benefits & $14(27.5 \%)$ & 37 (72.5\%) & \\
\hline
\end{tabular}


Table 6. Logistic regression result.

\begin{tabular}{|c|c|c|c|c|c|c|c|c|}
\hline \multirow{2}{*}{ Variable } & \multirow{2}{*}{ B } & \multirow{2}{*}{ S.E. } & \multirow{2}{*}{ Wald } & \multirow{2}{*}{ df } & \multirow{2}{*}{ Sig. } & \multirow{2}{*}{ Odds Ratio } & \multicolumn{2}{|c|}{ 95\% C.I. for EXP (B) } \\
\hline & & & & & & & Lower & Upper \\
\hline Job Security No & 2.472 & 0.977 & 6.407 & 1 & $0.011^{*}$ & 11.84 & 1.747 & 80.320 \\
\hline \multicolumn{9}{|c|}{ Part of job (Reference: Disagree) } \\
\hline Agree & 0.935 & 0.988 & 0.896 & 1 & 0.344 & 2.548 & 0.367 & 17.681 \\
\hline Indifferent & 1.089 & 1.039 & 1.100 & 1 & 0.294 & 2.972 & 0.388 & 22.763 \\
\hline \multicolumn{9}{|c|}{ Literacy (Reference: Diploma) } \\
\hline Below $10^{\text {th }}$ & 1.039 & 1.007 & 1.064 & 1 & 0.302 & 2.826 & 0.392 & 20.350 \\
\hline $10^{\text {th }} \mathrm{Gcmp}$ & 3.478 & 1.388 & 6.281 & 1 & $0.012^{*}$ & 32.39 & 2.134 & 49.719 \\
\hline \multicolumn{9}{|c|}{ Legal knowledge (Reference: No) } \\
\hline Yes & 1.149 & 0.843 & 1.858 & 1 & $0.043^{*}$ & 0.317 & 0.061 & 1.654 \\
\hline \multicolumn{9}{|c|}{ Salary (Reference: Above 333.31 Birr) } \\
\hline Below 333.31 & -1.507 & 0.94 & 2.571 & 1 & 0.109 & 0.222 & 0.035 & 1.398 \\
\hline \multicolumn{9}{|c|}{ Tips (Reference: Below 21.2 Birr) } \\
\hline Above 21.2 Birr & 0.354 & 0.859 & 0.170 & 1 & $0.046^{*}$ & 1.425 & 0.264 & 7.679 \\
\hline \multicolumn{9}{|c|}{ Dependent (Reference: No) } \\
\hline Yes & 1.819 & 1.106 & 2.707 & 1 & $0.041^{*}$ & 6.166 & 0.706 & 53.840 \\
\hline Constant & -0.337 & 1.089 & 0.096 & 1 & 0.757 & 0.714 & & \\
\hline
\end{tabular}

*Significant at 5\% level of significance.

contradict when seen from the waiters and managers stand. Moreover, other enforcement related issues have been detail discussed in this section.

The government institution the labor proclamation sought to be established in regional government is Bureau of Regional Labor and Social Affairs. Dire Dawa Administration Labor and Social Affairs Bureau is established with a mandate to assure the implementation of the labor law. The Bureau set up Law enforcement \& inspection department composed of two personnel's, to supervise the implementation of the law. The department employed different modalities to inspect whether the work conditions are observed or not. The first one is by visiting workplaces without prior notice of the employer and inquire/ascertain whether working condition are observed. Besides observation questioners to be filled by the employers will be distributed. The questions include among other things, the normal working hours of workers, whether employees are granted weekly rest day annual leave, maternity leave \& other leaves and whether overtime payment is paid in case where employees work for long hours.

The validity of responses was also cross checked by interviewing workers independently. Most of the time Employers do not admit the existence of violations of working time regulations. Those who admit used to deny it is employer driven or workers are paid overtime payment. That is, the employers do not compel to work for extra hours; it is the workers who insist to work for long hours. However, when workers asked independently they claim that it is the employer who compels them to stay long and they are working extra hours because of fear.

But when asked in the presence of the employer, workers usually start to reverse what they have said independently and justify that it is beneficial because they will make additional money. This phenomenon reflects the mechanics of work place power relations between the worker and employer. That is the employer has the upper hand in the relation and the bargaining power of waiters is too insignificant. Thus workers have little choice regarding working long hours and are expected to work additional hours. In this case, fearing dismissal or other penalties—in general perceived job insecurity—can be a driver for working long hours. Besides it is also 
an indication of the trust they had on the bureau in maintaining their interest.

The measures the inspectors can and have been taking in case they found any violation of law are of different kind. The first one is mere legal support. In this stage inspectors give an advice if the violation is due to lack of legal awareness and capacity to implement the law. If the problem still persists it will give an instruction to take a corrective measure within a given period of time. Upon failure of the employer to take such steps within the given time after receiving instructions and the problem is grave they will report the matter to higher officials so that they will take other administrative measures.

What the inspectors believe grave problem is a situation which causes or likely to cause an immediate harm to the body or health of employees. For them violation of working time regulation are not as such problems which attract their attention. Surprisingly, inspectors believe that working for long hours is not a problem at all, what concerns him is that the worker shall receive proportional payment.

As discussed in chapter two there are bulk of researches which show the negative impact of long working hour on the health of the worker by causing or aggravating disease, increase the likelihood of employment injuries. It would also affect the social responsibility of workers. In addition, long working hour has a macro-economic implication by reducing labour productivity and narrowing employment opportunities. There researchers observe attitude problem of inspectors on the relevancy of working time regulations.

Though the inspectors have the power to prosecute employers who violates working time regulations before criminal court, they have never tried it. The reason is that criminal measures in labor case are not advisable taking the nature of proceedings the maximum punishment to be awarded in to consideration. By their nature court proceedings are not only time taking and costly, but also criminal case requires them to prove beyond reasonable doubt to held the defendant liable which makes it to tiresome, even at times lose the case even there are evidences.

Having this nature of court proceeding in criminal cases, the maximum punishment the court can order is 500 birr fine which is too petty to employers who are financially strong most of the time. This petty punishment may not neither rehabilitate the offender nor it deter others from the offence. At times, the litigation cost might even exceed the penalty. Therefore, criminal remedy provided in the law is not efficient for the implementation of the law.

One of the functions of the bureau as enshrined under Art. 173(5) \& 177(6) is to deliver necessary trainings essential for the implementation of the law. Previously the bureau has been delivering trainings to create legal awareness to employees and employers once or twice year. But, the trainings do not address all industry. Especially, it was limited to waiters from Hotels with start. Insignificant no of waiters working in non stared hotels, if not nothing at all, are beneficiaries of the trainings. This fact is reflected in the data collected from waiters which shows that, great majority of waiters working in stared Hotels are aware of the working time regulation, compared to their counterparts. Now the bureau gave-up to deriver trainings due to budget constraints.

The bureau also lacks the necessary resources (human, material and financial) to discharge its functions effectively. Compared to thousands of work places in which labor inspectors are expected to supervise, two inspectors are insufficient. Due to resource constraint the annual plan of the bureau is to supervise only 50 work places.

In relation to resource and budget constraint, the bureau could not be able to collect and compile statistical data bureau of working conditions according to Art. 177(5) \& 176(6). The list of employers and number of employees is not available in the bureau. The problem is not fully attributable to limited resources. It can be gathered from concerned offices and organizations had there been a commitment from the Berea bureau corporation from others. In general the legal enforcement machinery is full of problems and not effective enough to implement the working time regulation.

\section{Discussion}

The study has shown that demographic factors such as age, gender, education, marital status and existence of dependents associated with long working hours. Age wise there were 3 minors (2.7\%) working for longer hours than the legal limit 42 hours. Gender difference has also been a factor though at insignificant margin to show difference on working overtime - of the male respondents (84.5\%) and of the females (82.5\%) work overtime. Most importantly, literacy level is found out to have been inversely related to overtime work, i.e. those with better level of education were not exposed to doing longer hours compared to those having lesser level or no educa- 
tion. This is in line with previous studies which indicated that level of education affects length of hours of workers (Kuhn \& Lozano, 2005). Probably those who have good education will have better awareness of legal knowledge and ask for their rights. Meanwhile, waiters with better level of education work in hotels with star than the rest.

With regard to dependants, the study indicated that those who have dependents $100 \%$ of the 47 of the respondents, irrespective of the type of hotel they were working in, are working overtime. This vividly depicts that having dependent adds an additional obligation on waiters to make more money and hence work for longer hours. The result is inconformity with other study (Kodz et al., 2003).

The study has also shown that there are significant gaps of legal awareness, both general legal knowledge of employment law, and specifically those rules relating to daily and average weekly working hours. Of the total respondent waiters $8.3 \%$ of them stated that they do not have agreement with their employers, while $76.6 \%$ of those who asserted to have contracts said it was oral agreement. On the other side, 17.4\% of the managers also asserted that they have had oral agreements with their workers. In addition, asked about the nature of the contract, whether it is for definite or indefinite period, 47 waiters (54\%) responded that it is for definite period. In light with the law, once they are allowed to work the presumption is taken that there is a binding agreement with their employer, and that the employer should give the worker a written and signed statement containing the requirements specified by law within 15 days. The nature of the contract is also defined by the law and that it relates to the nature of the work not on the time set by the parties to the contract.

Pertaining to the length of hours one is subjected to work, most waiters do not negotiate the length of hours they need to work and that $57.9 \%$ of them indicated that they do not know the existence of a law delimiting working hours. Even from those who claimed to know the limits few of them do not exactly tell the legal limits. There is a significant difference between those working in hotels with star (80\%) and the waiters working in other places (36.8\%). Managers were also questioned about the normal working hours and that 23 (95.8\%) of them claimed to know the rules 12 (52\%) of them indicated beyond the average legal limit i.e. 48 hrs per a week.

In addition, there is discrepancy between the perceptions of the waiters whether they have been working longer hours and the legal stipulations. Of the total respondents 26 (21.5\%) of them believe that they are not working longer hours but $90.1 \%$ of them are working overtime as per the legal standard and only $9.9 \%$. Of course, there is a difference between daily overload and weekly overload of the waiters. In addition, some of those who were not working overtime also indicated that had it not been for some health, social or family related issues; they might participate on overtime work.

Moreover, weekly rest is not granted to waiters as indicted by 57 (48.3\%) of them, and few of them asked for it but denied the chance. To that end, 6 (24\%) of the managers also confessed that they do not respect the weekly rest day for waiters. Apart from this, the managers indicated that they do not meet other legal requirements such as providing necessary training, leaves and the like. However, researches indicated that providing training, allowing unionization has significant effect to ensure a better protection of the rights of workers (Peetz, 2003). These all facts indicted that there existed a manifest lack of legal awareness from both waiters and managers perspectives.

The study has identified that monetary issues including salary, tips, service charges and other benefits contributed to longer working hours of the waiters. The mean salary for waiters working in hotels with stars is $328 \mathrm{Br}$ while the average salary for other waiters is $334 \mathrm{Br}$. This slight difference is justified on the service charges paid to those working in hotels with start (average $180 \mathrm{Br}$ per month) as part of their salary. In general, most waiters, $71.5 \%$ of them, are not satisfied with their payments; however, $60.4 \%$ of the total respondents still insisted to work overtime even if salary increment is made. $50 \%$ of the managers also said that the payments are not sufficient for waiters. In addition, waiters get an average of $19 \mathrm{Br}$ (for those working in hotels, cafes and restaurants) and 29.3 $\mathrm{Br}$ (in hotels with stars) per day; and the more they stay service the more money they make. This has also forced them to stay longer in their works. The availability of other benefits including food and at times shelter made worker to be more submissive to all the impositions from their employers. These are all consistent with the findings of other researchers (Mehran, 2005; Dawson, McCulloch, \& Baker, 2001).

It is also evident from the study that most waiters considered working for longer hours as a norm for their post. To that end, $54.7 \%$ of the waiters working in hotels without star and 53.3\% of those working in hotels with star disclosed this fact. This coupled with the observed understaffing indicated by waiters, (50\%) half of them rep- 
lied that their institutions are understaffed contrary to the view of employers; kept them work for longer hours than what the law required of them (Laurence et al., 2004; Kodz et al., 2003).

The study further identified that the existence of fear of losing one's job or simply stated job security has been a contributing factor. Of the total waiters working in hotels without star $34 \%$ of them indicated it as a factor for working longer hours while $13.3 \%$ of those working in Hotels with star opted it as a reason. This indicates that a significant number of waiters do not dare to challenge their employers so as to get their legal entitlements. Majority of the waiters responded that even after knowing their rights they may not request their right fearing risk of being fired. In tune with this, $27.8 \%$ of the managers responded that if a waiter refuses to work more than eight hours he would face risk of dismissal. The information acquired from the interviewed judge, i.e. worker only request overtime and other entitlements after they got fired by their employers; also substantiates the existence and magnitude of such a fear.

Moreover, the data acquired from waiters indicated that they do not know what to do the moment they consider their rights have been violated, and most of those who appeared to confront their employers end up dismissed from their jobs. The officer from the labor and Social Affairs Bureau also indicated that the regulatory mechanisms, including the punishment schemes for those who do not respect the regulations of working time, are so weak and the office lacked the necessary financial and man power given the number of employers it should monitor. These factors contributed negatively for the respect of the legal limits Ethiopia has adopted. The fact that these issues contribute for long working hours has been established by researches done in different countries (Kodz et al., 2003; Dawson, McCulloch, \& Baker, 2001).

Generally, this study scientifically established that gender, age, the existence of dependents, insufficient salary, understaffing, attitude of waiters, fear of being fired, lack of legal awareness, and absence of effective regulatory mechanisms contributed for the poor level of respecting the working time regulation of waiters in Dire Dawa Administration.

\section{Conclusion and Recommendations}

\subsection{Conclusion}

The study has probed into the contributing factors for longer working hours of waiters in Dire Dawa Administration. From the data gathered, it has been revealed that out of 121 respondents, 112 (90.1\%) of them (for weekly average) and 101 (83.5\%) of them (for daily limit) are working beyond the legal limits 48 eight hours average for a week or eight hours per a day. To investigate the factors, it has looked into demographic, socioeconomic, work and employment related, and legal enforcement related variables vis-à-vis the dependent factor i.e. working over legally provided limit or not.

The study scientifically proved that attitude of the worker about the nature of their work (accepting it as a norm), job security, level of education, legal knowledge, the amount of salary, tips and other benefits, social and existences of dependents have contributed for the longer hours working of waiters.

Most importantly, it has been found out that there exists lack of legal awareness of the laws from both the employers and waiters perspective. Those waiters who have legal knowledge about the length of hours they are expected to work were found to be less exploited (80.4\%) compared to those who have got no awareness of this law (85.7\%). Those who do not have and/or know about the length of hours they are expected to work happen to work more overload than those who know their limits. In addition, when a worker stays for longer hours on exceptional situations the law permits, there has to be a commensurate payment to that end. But the majority of works done by waiters were made without payments for them (only 3 individuals asserted they were paid overtime). Moreover, in the majority of the cases, no weekly rest day was given to workers. Managers do not know or respect legal obligations towards their workers such as creating not conducive working environment, providing weekly rest day, and different leaves recognized by law. This factors need to be addressed sooner than later.

It has also been noted that there are tendencies of not requesting for entitlements by workers who come to know their rights for different reasons. The basic one is being afraid of possible retaliation from their employers. Those who go for it, either their employers would not give them the required responses, or end up being fired.

In addition, the existence of dependents on waiters and related socio-economic factors forced them to work for longer hours to get the money they need for their livelihoods. The study indicated that all the respondents who have dependents work for longer hours. In the meantime, waiters, who get more that the average tips, 
whether working in hotels with star or not, work for longer hours than those who earn below the mean. This shows the more they stay in service the more money they make. Furthermore, waiters who responded that they got other benefits such as food and shelter facilities from their employers work longer hours than those who do not.

Salary has also been, though not that significant, found to be a factor. Those who get below the average salary $333 \mathrm{Br}$ happen to less likely work longer hours compared to those who earn above the mean score. Moreover, the level of education also is inversely related to working for longer hours in both hotels with stars and without stars. Those with better level of education tend to work lesser hours.

The logistic regression result indicated that the afore-stated factors have significant contributions for longer working hours. To that end, waiters that reported to have legal knowledge are about (0.317) less likely to work overload, and those who reported to feel insecure about their job are 11.846 times more likely to work overload than those who do not feel so. Regarding the tip they receive, waiters getting a tip above 21.2 Birr are 1.425 $(0.264,7.679)$ times more likely to work overload than those getting a tip less than the average tips. Waiters those reported to have dependents are 6.166 times more likely to work overload than respondents living without any dependent. Literacy status analysis also resulted that waiters who are only Grade $10^{\text {th }}$ complete are 32.392 times more likely to workload than respondents with Diploma level educational background.

Moreover, the study found out that there are problems with regard to regulatory mechanisms. To begin with, the Labour and Social Affairs Bureau of the administration could not monitor the effectiveness of enforcement of working time regulations. For the Bureau is not equipped with the necessary human and material constraints. Meanwhile, insufficient criminal penalty for violation of working time regulations makes the power of the Bureau, to affect behaviors of employers and the legal protection thereof, fruitless. Personal attitudes of personnel's of the Bureau which simplify the relevance of working time regulation might have its own share in the lenient administration of the problem. In general the legal enforcement machinery not effective enough to implement the working time regulation.

\subsection{Recommendations}

Based on the findings of the research, the researchers recommend the following points:

> Art. 184 (1) of labour Procl. No. 377/2003 shall be amended to increase the fine penalty and include imprisonment where employer violates working hour regulation.

> In order to maintain employees' job security, Art. 184 (2) of labour Procl. No. 377/2003 shall be amended to increase the fine penalty and include imprisonment where employees are fired or penalized by the employer as a result of claiming or exercise their rights.

$>$ A law shall be enacted to set the minimum wage in the private sector.

> Dire Dawa Administration Labour and Social Affairs Bureau shall be equipped with the necessary human, material resources. Sufficient budget shall also be allocated to the Bureau considering the breadth of its function.

$>$ Trainings shall be delivered to employers on the negative impacts of long hours working to the employer and workers.

> Capacity building trainings on the objective of working time regulations and the negative impacts of long working hour shall be delivered to professional of the Bureau.

$>$ The Bureau shall work in coordination with other government organs and organizations so as to efficiently discharge its obligations.

$>$ Legal awareness trainings shall be delivered to both the workers and employers.

$>$ An effort has to be made so as to increase the bargaining power of employees through trade unions.

\section{References}

Baker, A., Heiler, K., \& Ferguson, S. A. (2003). The Impact of Roster Changes on Absenteeism and Incident Frequency in an Australian Coal Mine. Occupational Environmental Medicine, 60, 43-49. http://dx.doi.org/10.1136/oem.60.1.43

Dawson, D., McCulloch, K., \& Baker, A. (2001). Extended Working Hours in Australia: Counting the Costs. Adelaide: Centre for Sleep Research.

Ellen, G., Bond, J. T., Kim, S. S., Backon, L., Brownfield, E., \& Sakai, K. (2004). Over Work in America: When the Way We Work Becomes Too Much. New York: Families and Work Institute.

Glezer, H., \& Walcott, I. (1999). Work and Family Life—Reciprocal Effects. Family Matters, 52, 69-74. 
Harrington, J. M. (2001). Health Effects of Shift Work and Extended Hours of Work. Occupational Environmental Medicine, 58, 68-72. http://dx.doi.org/10.1136/oem.58.1.68

Harrison, T., \& Horne, J. A. (2000). The Impact of Sleep Deprivation on Decision Making: A Review. Journal of Applied Experimental Psychology, 6, 236-249. http://dx.doi.org/10.1037/1076-898X.6.3.236

Hogarth, T., Hasluck, C., Pierrre, G., Winterbotham, M., \& Vivian, D. (2001). Work-Life Balance 2000: Baseline Study of Work Life Balance Practices in Great Britain. Warwick: Institute for Employment Research, Warwick University.

International Labour Office (1967). Hours of Work: A World Survey of National Law and Practice. Geneva: ILO.

Kirkcaldy, B. D., Trimpop, R., \& Cooper, C. L. (1997). Working Hours, Job Stress, Work Satisfaction, and Accident Rates among Medical Practitioners and Allied Personnel. International Journal of Stress Management, 4, 79-87.

Kodz et al. (2003). Working Long Hours: A Review of the Literature. Department of Trade and Industry, Employment Relations Series No. 16, United Kingdom.

Kuhn, P., \& Lozano, F. (2005). The Expanding Workweek? Understanding Trends in Long Work Hours among US Men, 1979-2004. NBER Working Paper 11895.

Laurence, H. et al. (2004). Extended Working Hours Review. Final Report.

Lee, S., McCann, D., \& Messenger, J. C. (2007). Working Time around the World: Trends in Working Hours, Laws and Policies in a Global Comparative Perspective. Geneva: International Labour Organization.

Mehran, F. (2005). Measuring Excessive Hours of Work, Low Hourly Pay, and Informal Employment through a Labour Force Survey: A Pilot Survey in the Philippines. Presented at The UNECE/ILO/Eurostat Seminar on the Quality of Work, Geneva, 11-13 May 2005.

Murray, J. (2001). Transnational Labour Regulation: The ILO and EC Compared. The Hague: Kluwer Law International.

Peetz, D. (2003). Race against Time: Extended Hours in Australia. Brisbane: Griffith University.

Spurgeon, A. (2003). Working Time: Its Impact on Safety and Health. Geneva and Incehon: ILO and Korean Occupational Safety and Health Research Institute.

Van der Hulst, M. (2003). Long Work-Hours and Health. Scandinavian Journal of Work, Environment \& Health, 29, 171188. http://dx.doi.org/10.5271/sjweh.720 


\section{Annex 1. Questionnaire for Waiters}

This questionnaire has been prepared in order to examine the contributing factors of waiters working for longer hours than the law stipulates in Ethiopia, particularly in Dire Dawa. Your response will only be used for research purposes and everything remains confidential. We request your cooperation in filling out this questionnaire and provide us with accurate information.

Thank you for your cooperation on behalf of the beneficiaries of this study.

\section{Employer:}

General information:

Age:

Sex:

Marital status Single Widowed Divorced/Separated Married

Level of education

Do you have any dependent? Children parents others

Salary: Other benefits: Tips:

1. How many years in total have you been working at this workplace? By workplace we mean the site or location at, or from, which you work.

2. Do you have contract of employment?
A. Yes,
B. No

3. Is the contract of employment written or oral?
A. Written
B. Oral

4. Is your job permanent, or is it temporary?
A. Permanent
B. Temporary
C. Probation period

5. If you have contract of employment, is there an agreement pertaining to the length of hours you should serve?
A. Yes,
B. No
C. I don't know

6. If your answer is yes for Q.5, for how long is it?

1. Per day

2. Per week

7. Do you know the existence of laws delimiting the maximum working hours in Ethiopia for workers like you?
A. Yes,
B. No

8. If your answer is yes for Q. 5 , specify it
A. per day
B. Per week.

9. How many hours do you usually work (one month average), including any overtime or extra hours?
A. Per day
B. Per week

10. Do you work overtime or extra hours?
A. Yes
B. No

11. Why do you work extra hours?
A. Employer compelled to work
B. It's required as part of my job
C. I don't know the legal protection thereof
D. I want to work due to personal reason
E. Any otherreason, please specify, 
12. If you do not work, why not?
A. I am legally entitled not to work
B. Existence of sufficient workers
C. I don't want to work extra hours
D. Employer does not allow me to work for extra hours

E. Any other reason, please specify,

13. Do you really want to work for extra hours?
A. Yes
B. No

14. If you want to work, why? Whether you actually working extra hours or not.
A. I will earn additional money
B. There is an overtime allowance
C. I want to stay out of home
D. I enjoy the work
E. I will be given time off some other day where I need it
F. Any other reason, please specify,

15. If you do not want to work extra hours, why not? Whether you actually working extra hours or not.
A. Health problem
B. Family responsibility
C. Education
D. Social business
E. Any other reason, please specify,

16. When do you work extra hours? You can encircle more than one instance.
A. Always
B. When there is an urgent work
C. In lieu of absent worker
D. On holydays
E. Special arrangements or occasions
F. If any other, please specify

17. How many overtime or extra hours do you work per a week on average, whether paid or unpaid?

18. Are you normally paid or given time off later when you work overtime or extra hours?
A. I never work overtime or extra hours
B. I am normally paid
C. I normally take time off later
D. I am sometimes paid and sometimes take time off later
E. None of these

19. If you know that you are not obliged to work extra hours, have you claimed your right not to work for extra hours?
A. Yes
B. No

20.If your reply for the above question is "Yes" what responses did you get from your employer?

21. Had you known your right, would you claim your right not to work for extra hours?
A. Yes
B. No

22.If you do work overtime or extra hours knowing or after you are let to know your right, what is your reason? (You can encircle more than one choice)
A) Fearing risk of being fired and absence of other alternatives
B) Considering it is beneficial to yourself
C) There is an overtime allowance
D) Lack of opportunity and not knowing where to ask 
E) Pre-occupied by the feeling that the employer will not listen to your problem

F) I want to stay out of home

G) Expecting promotion

H) Any other, specify

23. Assume that your salary increases reasonably, will you still be willing to work for extra hours?
A. Yes

B. No

24. Do you have a weekly rest day?
A. Yes,
B. No

25. If your answer for the above question is "Yes" explain it

26.If your answer for the above question is "No" why not?

A. I don't want to have

B. Not permitted

C. I don't know whether I have a right

27. Do you get any sort of leave? (sick, annual, family ...)
A. Always paid leave
B. Always unpaid leave
C. Sometimes paid sometimes unpaid as the case may be
D. Not at all

How satisfied are you with the following aspects of your job?

Very dissatisfied $=1$; Dissatisfied $=2$; neither satisfied nor dissatisfied $=3$; Satisfied $=4$; Very satisfied $=5$

Working environment
The amount of pay you receive
Return of extra hour work
The respect you get from supervisors/line managers
Working time schedule
Relation with co-workers
Relation with customers

Do you agree, or disagree, with the following statements about your job?

Strongly agree $=5$; Agree $=4$; Neither agree nor disagree $=3$; Disagree $=2 ;$ Strongly Disagree $=1$

\begin{tabular}{|c|c|c|c|c|c|}
\hline & 5 & 4 & 3 & 2 & 1 \\
\hline \multicolumn{6}{|l|}{ I feel my job is secure in this workplace } \\
\hline \multicolumn{6}{|l|}{ My job requires me to work long hours } \\
\hline \multicolumn{6}{|l|}{ I am working for long hours } \\
\hline \multicolumn{6}{|l|}{ My working time is convenient for other social business } \\
\hline \multicolumn{6}{|l|}{ I am beneficial of working extra hours } \\
\hline \multicolumn{6}{|l|}{ There is working time flexibility in my work place } \\
\hline \multicolumn{6}{|l|}{ I do not want to work extra hours } \\
\hline I have a chance of promotion & & & & & \\
\hline
\end{tabular}




\section{Annex 2: Questionnaire for Managers}

This questionnaire has been prepared in order to examine the contributing factors of waiters working for longer hours than the law stipulates in Ethiopia, particularly in Dire Dawa. Your response will only be used for research purposes and everything remains confidential. We request your cooperation in filling out this questionnaire and provide us with accurate information.

Thank you for your cooperation on behalf of the beneficiaries of this study.

1. Name of the Hotel:

2. Your Position:

3. Your relation with the owner of the hotel

4. How many years have you been working at this hotel?

5. Number of employees in the hotel

6. Do you have contract of employment with your employees?

C. Yes,

D. No

7. Is the contract of employment written or oral?
C. Written
D. Oral
E. Other form, specify

8. How do you hire the employees at your organization?
a. By notice and competition
b. Through Broker
c. Blood relation/affinity
d. Other, specify

9. What is/are your main criteria of recruiting a waiter?
a. Sex related, specify the criteria
b. Level of education, specify the criteria
c. Experience, specify the criteria
d. Age, specify the criteria
e. Other, specify the criteria

10. What are the job descriptions of waiters?
a.
b.
c.

11. Do you permit waiters to be hired and work for other employers?
a. Yes, why
b. No, why

12. Are there waiters who work in other places?
a. Yes
b. No
c. I don't know

13. How do you determine the amount of waiters' salary?
a. Negotiation
b. Salary scale of the hotel
c. Other, specify

14. Do you think that their salary is sufficient for their livelihood?
a. Yes
b. No

15. List the problems/errors committed by waiters in there order of gravity.
b.
c.
d. 
16. What do you think is the solution to solve these problems? Please list them.
a.
b.
c.
d.

17. Is there any work rule (specific to your hotel)?
a. Yes
b. No

18. How do you rate the number of waiters in your hotel vis-a-vis the workload?
a. More than sufficient
b. Sufficient
c. Not sufficient

19. Do you provide trainings including capacity building trainings for waiters?
a. Yes
b. No

20. Are you a member of any workers' association?
a. Yes
b. No

21. Indicate the maximum daily and weekly working hours of an employee, according to the Ethiopian law.
a. Per day
b. Per week hour hour

22. List the types of leaves and rest days an employee is legally entitled to.
a.
b.
c.
d.
e.

23. Do you think the working environment is convenient for waiters?
a. Yes
b. No

24. How do you express the employee-manager relationship at your hotel?
a. Good
b. Fair
c. Bad

25. What do you think is the reason for the type of relation you indicated under Q.24?

26. For how long are waiters obliged to work per day at your hotel? (hours)

27. Are there situations in which waiters are required to work for longer hours than that mentioned above? Please, list them.
a.
b.
c.
d.

28. Do you think that waiters work for long hours?
a. Yes
b. No

29. What is the reason for letting waiters to work more than eight hours per day?
a. We can't afford to hire more employees.
b. To benefit them.
c. Work load.
d. It is their duty.
e. Other, specify 
30. If you have waiters working for not more than eight hours per day, what is the reason?
a. We have sufficient waiters
b. There is no work load
c. It is their right
d. Other, specify

31. Do waiters have weekly rest day?
a. Yes
b. No

32. Do waiters have rest on public holidays?

a. Yes

b. No

33. What do waiters get for working in weekly rest day or public holidays?
a. Over time payment
b. Leave in lieu of unutilized day
c. Nothing
d. Other, specify

34. Why do you allow waiters to work on public holidays?
a. Nature of the work obliged us so.
b. It is their duty.
c. Waiters want to work.
d. Other, specify

35. If they do not work on holidays, what do you think is the reason for that?
a. It is their right.
b. Waiters want to have time with family during holidays.
c. Other, specify

36. What measure(s) will you take if a waiter refuses to work more than eight hours per day?
a. Dismissal
b. Fine
c. Warning
d. Nothing
e. Other, specify 